\title{
Effects of Sputtering and Annealing Temperatures on MOS Capacitor with HfTiON Gate Dielectric
}

\author{
C.D. Wang, C.X. Li, C.H. Leung and P.T. Lai
}

\begin{abstract}
In this work, Al/HfTiON/n-Si capacitors with different sputtering and annealing temperatures are studied. Larger accumulation capacitance and flat-band voltage are observed for samples with higher sputtering or post-deposition annealing temperature. Gate conduction mechanisms are only affected by sputtering temperature slightly. The flat-band voltage shift and interface-state density at midgap under high-field gate injection and substrate injection are investigated, and the results imply electron detrapping in the gate dielectric.
\end{abstract}

\section{INTRODUCTION}

Continual scaling down of microelectronic devices requires ultra-thin gate dielectric, which results in unacceptable current leakage when conventional $\mathrm{SiO}_{2-}$ based gate oxide is used [1]. One solution is to use high dielectric constant (high- $k$ ) materials as the gate insulating layer [2], by which a physically thicker gate film can be used to significantly reduce the gate leakage while maintaining the same capacitance equivalent thickness.

Many high- $k$ dielectrics incorporated on Si substrate have been investigated, such as $\mathrm{Al}_{2} \mathrm{O}_{3}$ [3], $\mathrm{Ta}_{2} \mathrm{O}_{5}$ [4], $\mathrm{TiO}_{2}$ [4], $\mathrm{La}_{2} \mathrm{O}_{3}$ [5], $\mathrm{Y}_{2} \mathrm{O}_{3}$ [6], $\mathrm{HfO}_{2}$ [7], $\mathrm{ZrO}_{2}$ [8], HfSiON [9], and HfLaON [10]. When applied to $\mathrm{Si}$ substrate, however, such materials do not have comparable qualities as $\mathrm{SiO}_{2}$ in thermal stability and electrically reliability. They either have too small conduction-band offset with $\mathrm{Si}\left(\right.$ like $\mathrm{Ta}_{2} \mathrm{O}_{5}$ and $\mathrm{TiO}_{2}$ ), or have too many fixed charges (like $\mathrm{Al}_{2} \mathrm{O}_{3}$ ), or are apt to moisture absorption (like $\mathrm{La}_{2} \mathrm{O}_{3}$ ), or have low crystallization temperature (like $\mathrm{TiO}_{2}$ and $\mathrm{Y}_{2} \mathrm{O}_{3}$ ) [11]. Among many candidates, Hf-based high- $k$ dielectrics are considered to be the most promising ones when taken overall properties into account [12], with HfTiON having relatively high $k$ value.

Several methods have been used to grow gate dielectric thin films, among which sputter deposition is commonly used nowadays as a physical vapor deposition method. As for sputter deposition, temperature is one important parameter which should influence the quality of the thin films. In addition, post-deposition annealing (PDA) is usually conducted after gate film deposition to acquire good dielectric quality. PDA temperature is very critical and should be chosen elaborately, for too low temperature may not be effective to remove defects while too high temperature may result in film crystallization [13]. In this work, the effects of sputtering and PDA temperatures on

978-1-4244-4298-0/09/\$25.00 @2009 IEEE
C.D. Wang, C.X. Li, C.H. Leung and P.T. Lai are with Department of Electrical and Electronic Engineering, the University of Hong Kong. Email: laip@eee.hku.hk

$\mathrm{Al} / \mathrm{HfTiON} / \mathrm{n}-\mathrm{Si}$ MOS capacitor will be studied. The gate leakage mechanism and dielectric reliability under highfield stress will also be investigated.

\section{EXPERIMENTS}

(100) phosphorus-doped silicon substrate with resistivity of $0.5 \sim 0.7 \Omega \cdot \mathrm{cm}$ was used to fabricate MOS capacitors. The wafers were first cleaned using the standard RCA process, and then were immediately transferred into the chamber of a sputter system. A thin layer of $\operatorname{HfTiN}(\sim 6 \mathrm{~nm})$ was deposited using reactive cosputtering of $\mathrm{Hf}$ and $\mathrm{Ti}$ targets in a $\mathrm{N}_{2} / \mathrm{Ar}$ ambience at different substrate temperatures: room temperature (RT), $200^{\circ} \mathrm{C}, 300^{\circ} \mathrm{C}$ and $400^{\circ} \mathrm{C}$, respectively. Post-deposition annealing was then conducted in dry $\mathrm{N}_{2}$ under different conditions $\left(1\right.$ minute at $500^{\circ} \mathrm{C}, 600^{\circ} \mathrm{C}$ and $700^{\circ} \mathrm{C}$ respectively), where HfTiN was transformed into HfTiON due to residual $\mathrm{O}_{2}$ in $\mathrm{N}_{2}$. For comparison, some samples did not receive the PDA treatment. Al with a thickness of $500 \mathrm{~nm}$ was evaporated and then patterned as gate electrode with an area of $7.85 \times 10^{-5} \mathrm{~cm}^{2}$. Finally, a forming-gas anneal was performed at $425^{\circ} \mathrm{C}$ for 20 minutes to make better electrical contact.

High-frequency capacitance-voltage and gate leakage current characteristics were measured at room temperature using HP4281A precision LCR meter and HP $4156 \mathrm{~A}$ precision semiconductor parameter analyzer, respectively. Also, high-field stress was imposed to examine the device reliability. The thickness of the dielectric layer was measured using spectroscopic ellipsometry (SE). All the measurements were performed under a dark ambience and electrically-shielded condition.

\section{RESULTS AND DISCUSSION}

In Fig. 1, it can be observed that the thickness decreases as the temperature of sputter deposition or PDA treatment increases. This is probably because when the substrate is heated at higher temperature during film deposition, surface diffusion of atoms is significantly increased so that better planarization and denser film are accomplished. For the same sputter deposition condition, especially at low deposition temperatures (RT and $200^{\circ} \mathrm{C}$ ), compared with samples without PDA treatment, PDA at $500^{\circ} \mathrm{C}$ and $600^{\circ} \mathrm{C}$ can reduce the thickness of dielectric layer significantly. For the samples with PDA at $700^{\circ} \mathrm{C}$, a pronounced reduction of dielectric thickness is observed 
compared with the samples under other PDA temperatures due to better densification at $700^{\circ} \mathrm{C}$.

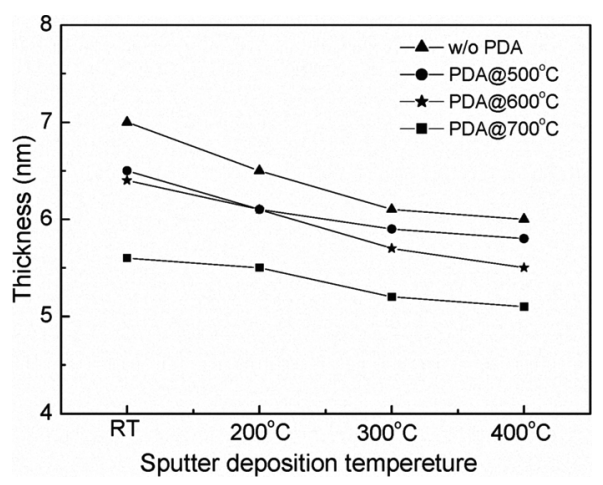

Fig. 1. Physical thickness of dielectric layer for samples with different sputter deposition and PDA temperatures.

High-frequency (1-MHz) capacitance-voltage (C-V) characteristics of the $\mathrm{Al} / \mathrm{HfTiON} / \mathrm{Si} \mathrm{MOS}$ capacitors are shown in Fig. 2. As to each panel in Fig. 2(a), for the same sputter deposition temperature, samples with PDA at $700^{\circ} \mathrm{C}$ have pronounced improvements in device performance, suggesting that the temperatures of $500^{\circ} \mathrm{C}$ or $600^{\circ} \mathrm{C}$ are not high enough to remove defects inside the devices. It can also be noticed that for samples with sputter deposition at RT or $200^{\circ} \mathrm{C}$, the higher the PDA temperature, the larger the accumulation capacitance is; while for samples with sputter deposition at $300^{\circ} \mathrm{C}$ or $400^{\circ} \mathrm{C}$, the samples without PDA have larger accumulation capacitance than those with PDA at $500^{\circ} \mathrm{C}$ or even at $600^{\circ}$, which is a direct result of in situ annealing effect. As the deposition temperature increases, its in situ annealing effect complements the inadequate of the PDA treatment, and thus the difference in accumulation capacitance for the samples in each group is weakened. On the other hand, in each group, larger flatband voltage $V_{f b}$ is observed for samples with higher PDA temperature suggesting an increase of positive charge trapping or hole trapping at higher PDA temperature. Such $\mathrm{V}_{\mathrm{fb}}$ trend is different from $\mathrm{HfO}_{2}$ gate dielectrics annealed in $\mathrm{O}_{2}$ ambient where $\mathrm{V}_{\mathrm{fb}}$ shifts negatively first and then shifts positively as the annealing temperature ranges from $550^{\circ} \mathrm{C}$ to $800^{\circ} \mathrm{C}$ [13]. In Fig. 2(b), at same PDA treatment, larger $V_{\mathrm{fb}}$ is shown obviously for the samples with the higher sputter deposition temperature. Also, it can be found from each panel that higher sputter deposition temperature leads to larger accumulation capacitance.

High-frequency (1-MHz) bidirectional C-V characteristics (not shown) suggest almost no $\mathrm{C}-\mathrm{V}$ hysteresis (no more than $20 \mathrm{mV}$ ) and no kinks near the inversion region for all the samples, indicating there are almost neglectable near-interfacial slow oxide traps [14, 15]. In addition, the bidirectional $\mathrm{C}-\mathrm{V}$ curves seems almost not affected by different sputter deposition and PDA temperatures, suggesting such near-interfacial slow oxide traps would not be created by in situ annealing or PDA treatment in $\mathrm{N}_{2}$ ambience.

Fig. 3 shows the gate leakage characteristics in accumulation region obtained for samples with PDA at $700^{\circ} \mathrm{C}$ but with different sputter deposition temperatures. It can be found that higher sputter deposition temperature
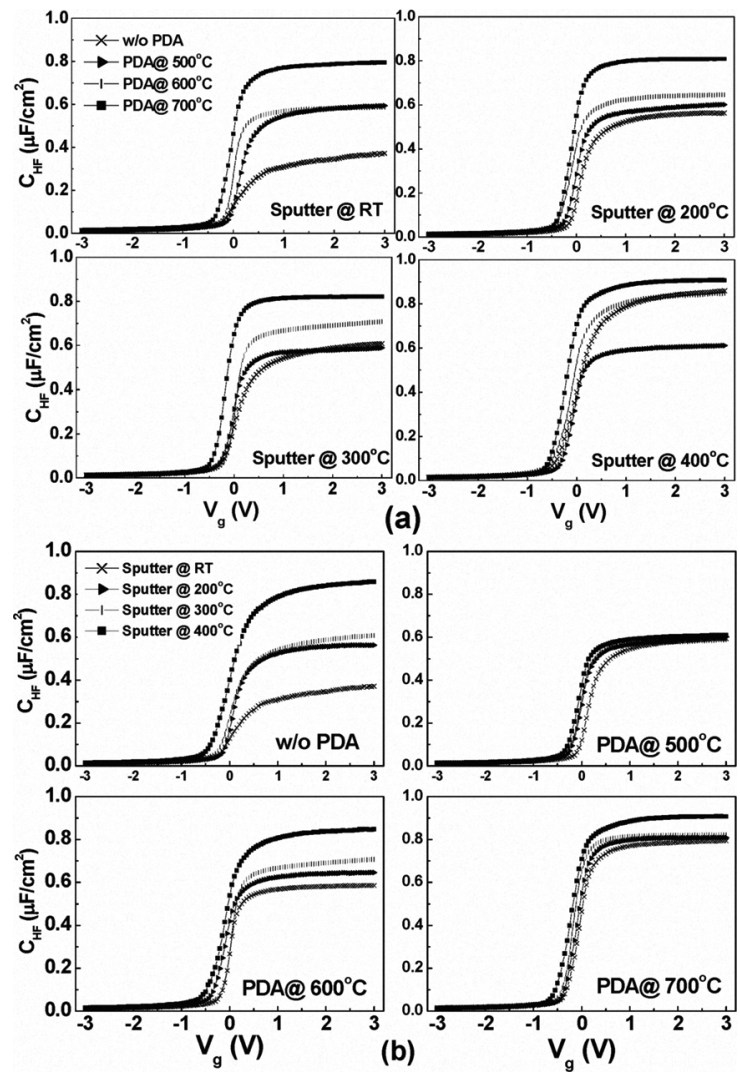

leads to relatively larger gate leakage. The insets of Fig. 3 Fig. 2. High-frequency $\mathrm{C}-\mathrm{V}$ characteristics $(1 \mathrm{MHz})$ of the Al/HfTiON/Si MOS capacitors: (a) each panel shows samples with same sputter deposition temperature but with different PDA treatments; (b) each panel shows samples with same PDA treatment but with different sputter deposition temperatures.

show the current conduction mechanisms at different voltage regions for the sample with sputter deposition at $400^{\circ} \mathrm{C}$. For an electric field less than $0.9 \mathrm{MV} / \mathrm{cm}$, the current can be fitted with the Schottky emission equation, $\ln \mathrm{J}_{\mathrm{g}} \propto \mathrm{E}^{1 / 2}$, where $\mathrm{E}$ is electric field in the dielectric. For an electric field larger than $0.9 \mathrm{MV} / \mathrm{cm}$, the current can be fitted by direct tunneling, $\mathrm{E} \times \ln \left(\mathrm{J}_{\mathrm{g}} / \mathrm{E}^{2}\right) \propto \mathrm{E}^{3 / 2}[16]$. Thus, at a low voltage, electrons at the surface of silicon after acquiring enough energy from the electric filed can overcome the potential barrier to form the gate leakage; while at a high voltage, electrons tunneling through the dielectric is the main process resulting in gate leakage. The results are in agreement with the former reports [16, 17]. Other samples have the same conduction mechanisms. By using the electron effective mass data reported [17], the $\mathrm{HfTiON} / \mathrm{Si}$ barrier height can be estimated coarsely to be in the range of $0.60 \sim 0.66 \mathrm{eV}$ when $\mathrm{m}^{*}=0.1 \mathrm{~m}_{0}$ is used, while in the range of $0.64 \sim 0.70$ $\mathrm{eV}$ when $\mathrm{m}^{*}=0.4 \mathrm{~m}_{0}$ is used, where $\mathrm{m}_{0}$ is free electron mass, and $\mathrm{m}^{*}$ is electron effective mass in dielectric. The small value of barrier height may be attributed to $\mathrm{Ti}$ [1]. It can be noted that different sputter deposition temperatures do not result in large dispersion of barrier height (no more than $60 \mathrm{mV}$ ). In addition, the small barrier height should 
account for the large gate leakage when HfTiON is used as dielectric layer.

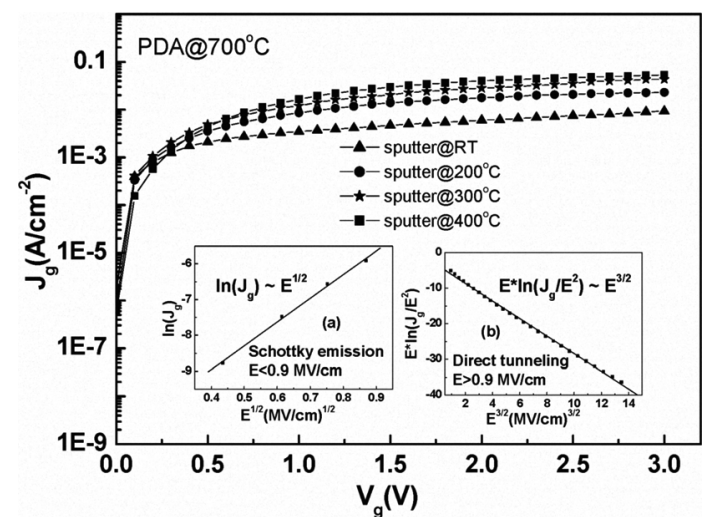

Fig. 3. Gate leakage characteristics at accumulation region obtained for samples with PDA at $700^{\circ} \mathrm{C}$ but with different sputter deposition temperatures. The insets show current conduction mechanisms at different voltage regions for the sample with sputter deposition at $400^{\circ} \mathrm{C}$, where scatters are experimental data, and straight lines are linear fitting.
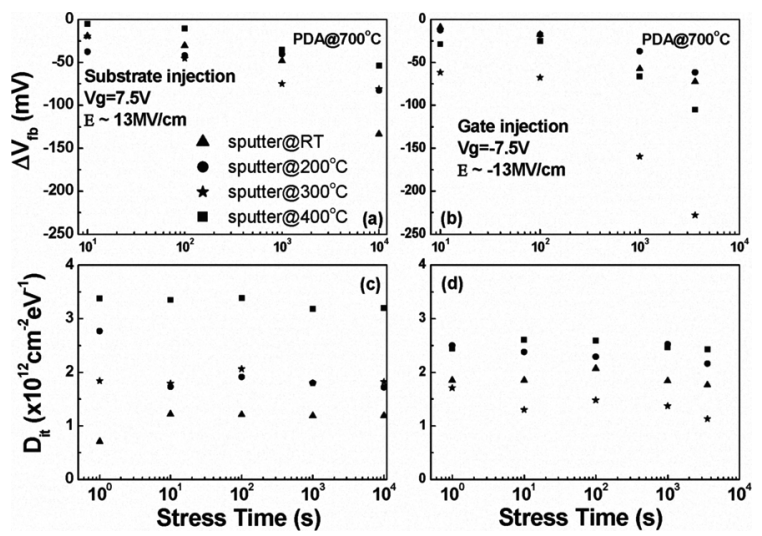

Fig. 4. Flat-band voltage $\left(\Delta \mathrm{V}_{\mathrm{fb}}\right)$ and interface state density $\left(D_{i t}\right)$ at midgap after a constant voltage stress for samples with PDA at $700^{\circ} \mathrm{C}$ but with different sputter deposition temperatures; (a) $\Delta \mathrm{V}_{\mathrm{fb}}$ and (c) $\mathrm{D}_{\text {it }}$ are substrate injection, $V_{g}=7.5 \mathrm{~V}$; (b) $\Delta \mathrm{V}_{\mathrm{fb}}$ and (d) $\mathrm{D}_{\text {it }}$ are gate injection, $\mathrm{V}_{\mathrm{g}}=-7.5 \mathrm{~V}$.

The change of flat-band voltage $\left(\Delta \mathrm{V}_{\mathrm{fb}}\right)$ and interfacestate density $\left(\mathrm{D}_{\mathrm{it}}\right)$ at midgap are studied under high-field stress $(\sim 13 \mathrm{MV} / \mathrm{cm})$, and the results are shown in Fig. 4. A negative shift of $\mathrm{V}_{\mathrm{fb}}$ is observed for the devices under gate injection $\left(\mathrm{V}_{\mathrm{g}}=-7.5 \mathrm{~V}\right)$, which is consistent with other works [18-20]. This is probably due to hole trapping or electron detrapping, or less efficient electron trapping than hole trapping. On one hand, new traps for holes may be created under high-field due to stoichometry variation [21] or strained bonds [22] or other unknown defects. On the other hand, it has been demonstrated that electron detrapping through tunneling is very effective in the highfiled range [23], and the cross section for electrons captured by holes decreases strongly at high electric filed [18]. Thus, although both electron and hole injection occur under gate injection, the trapped holes are not likely to be neutralized when a large amount of electrons flow through dielectric. To further understand the mechanism, substrate injection is also studied by which a positive biased voltage $\left(\mathrm{V}_{\mathrm{g}}=7.5 \mathrm{~V}\right)$ is applied to the gate. It is noticed that the $V_{f b}$ still shifts negatively as the stress time increases. Since only electrons are injected from substrate under substrate injection due to lack of holes in the metal electrode, the negative shift of $V_{f b}$ is more likely attributed to electron detrapping. For both gate injection and substrate injection, $\mathrm{D}_{i t}$ at midgap after each stress period is extracted from high-frequency $\mathrm{C}-\mathrm{V}$ trace by the Terman's method [24]. For each case, $D_{\text {it }}$ is almost independent of stress time and remains nearly constant for each sample, implying that very few interface states are generated by the high-field stress. The characteristics of $\mathrm{D}_{\text {it }}$ at midgap seem not influenced significantly by different sputter deposition temperatures since their values are in the same order for all the samples studied.

\section{CONCLUSION}

$\mathrm{Al} / \mathrm{HfTiON} / \mathrm{n}-\mathrm{Si}$ capacitors with different sputtering and annealing temperatures are fabricated and investigated. The results show that higher sputter deposition or PDA temperature reduces the physical thickness of dielectric layer, and also leads to larger accumulation capacitance and larger flat-band voltage as well. $500^{\circ} \mathrm{C}$ or $600^{\circ} \mathrm{C}$ are not high enough for PDA treatment while $700^{\circ} \mathrm{C}$ can significantly improve the device performance. Negligible $\mathrm{C}-\mathrm{V}$ hysteresis is observed for all the samples. Leakage characteristics show that the gate conduction is governed by Schottky emission at low filed and direct tunneling at high filed. Higher sputter temperature results in slightly smaller barrier height and thus relatively larger gate leakage. Negative flat-band voltage shift and almost constant interface-state density under high-field gate injection and substrate injection indicate electron detrapping in the gate dielectric.

\section{ACKNOWLEDGEMENT}

The work is supported by the University Development Fund (Nanotechnology Research Institute, 00600009) of the University of Hong Kong

\section{REFERENCES}

Y. Kamata, "High-k/Ge MOSFETs for future nanoelectronics," Materials Today. vol. 11, pp. 30-38, 2008.

[2] Y. Zhao, K. Kita, K. Kyuno, and A. Toriumi, "Dielectric and electrical properties of amorphous $\mathrm{La}_{1}-\mathrm{Ta}_{\mathrm{x}} \mathrm{O}$ films as higher-k gate insulators," Journal of Applied Physics, vol. 105, pp. 034103-5, 2009.

[3] G. D. Wilk, R. M. Wallace, and J. M. Anthony, "High-kappa gate dielectrics: Current status and materials properties considerations," Journal of Applied Physics, vol. 89, pp. 5243-5275, 2001.

[4] B. H. Lee, J. Oh, H. H. Tseng, R. Jammy, and H. Huff, "Gate stack technology for nanoscale 
devices," Materials Today, vol. 9, pp. 32-40, 2006.

[5] Y. H. Wu, M. Y. Yang, A. Chin, W. J. Chen, and C. M. Kwei, "Electrical characteristics of high quality $\mathrm{La}_{2} \mathrm{O}_{3}$ gate dielectric with equivalent oxide thickness of 5A," Electron Device Letters, IEEE, vol. 21, pp. 341-343, 2000.

[6] S. Guha, E. Cartier, M. A. Gribelyuk, N. A. Bojarczuk, and M. C. Copel, "Atomic beam deposition of lanthanum- and yttrium-based oxide thin films for gate dielectrics," Applied Physics Letters, vol. 77, pp. 2710-2712, 2000.

[7] A. Callegari, E. Cartier, M. Gribelyuk, H. F. Okorn-Schmidt, and T. Zabel, "Physical and electrical characterization of Hafnium oxide and Hafnium silicate sputtered films," Journal of Applied Physics, vol. 90, pp. 6466-6475, 2001.

[8] O. Bethge, S. Abermann, C. Henkel, and E. Bertagnolli, "Low temperature atomic layer deposition of high-k dielectric stacks for scaled metal-oxide-semiconductor devices," Thin Solid Films, vol. 517, pp. 5543-5547, 2009.

[9] S. Toyoda, H. Kamada, T. Tanimura, H. Kumigashira, M. Oshima, G. L. Liu, Z. Liu, and K. Ikeda, "Thermal stability in a-Si/HfSiO(N)/Si gate stack structures studied by photoemission spectroscopy using synchrotron radiation," Applied Physics Letters, vol. 93, pp. 182906-3, 2008.

[10] Q. Xu, G. Xu, W. Wang, D. Chen, S. Shi, Z. Han, and T. Ye, "Study on characteristics of thermally stable HfLaON gate dielectric with TaN metal gate," Applied Physics Letters, vol. 93, pp. 252903-3, 2008.

[11] H. Wong and H. Iwai, "On the scaling issues and high-[kappa] replacement of ultrathin gate dielectrics for nanoscale MOS transistors," Microelectronic Engineering, vol. 83, pp. 18671904, 2006.

[12] E. P. Gusev, V. Narayanan, and M. M. Frank, "Advanced high- $k$ dielectric stacks with polySi and metal gates: recent progress and current challenges," IBM J. Res. Dev., vol. 50, pp. 387410, 2006.

[13] B. Sen, H. Wong, V. Filip, H. Y. Choi, C. K. Sarkar, M. Chan, C. W. Kok, and M. C. Poon, "Current transport and high-field reliability of aluminum/hafnium oxide/silicon structure," Thin Solid Films, vol. 504, pp. 312-316, 2006.

[14] C. Chi On, S. Ramanathan, B. B. Triplett, P. C. McIntyre, and K. C. Saraswat, "Germanium
MOS Capacitors Incorporating Ultrathin High-k Gate Dielectric," Electron Device Letters, IEEE, vol. 23, pp. 473-475, 2002.

[15] N. A. Chowdhury, R. Garg, and D. Misra, "Charge trapping and interface characteristics of thermally evaporated $\mathrm{HfO}_{2}$," Applied Physics Letters, vol. 85, pp. 3289-3291, 2004.

[16] H. Wang, Y. Wang, J. Zhang, C. Ye, H. B. Wang, J. Feng, B. Y. Wang, Q. Li, and Y. Jiang, "Interface control and leakage current conduction mechanism in $\mathrm{HfO}_{2}$ film prepared by pulsed laser deposition," Applied Physics Letters vol. 93, pp. 202904-3, 2008.

[17] F.-C. Chiu, "Interface characterization and carrier transportation in metal/ $/ \mathrm{HfO}_{2} /$ silicon structure," Journal of Applied Physics, vol. 100, pp. 114102-5, 2006.

[18] D. J. DiMaria, Z. A. Weinberg, and J. M. Aitken, "Location of positive charges in $\mathrm{SiO}$ [sub 2] films on $\mathrm{Si}$ generated by vuv photons, $\mathrm{x}$ rays, and high-field stressing," Journal of Applied Physics, vol. 48, pp. 898-906, 1977.

[19] L. Wei-Yip, C. Byung Jin, J. Moon Sig, L. Ming-Fu, D. S. H. Chan, S. Mathew, and K. Dim-Lee, "Charge trapping and breakdown mechanism in $\mathrm{HfAlO} / \mathrm{TaN}$ gate stack analyzed using carrier separation," Device and Materials Reliability, IEEE Transactions on, vol. 4, pp. 696-703, 2004.

[20] N. Rahim and D. Misra, "NBTI behavior of $\mathrm{Ge} / \mathrm{HFO}_{2} / \mathrm{Al}$ gate stacks," in Reliability Physics Symposium, 2008. IRPS 2008. IEEE International, pp. 653-654, 2008.

[21] J. S. Johannessen, W. E. Spicer, and Y. E. Strausser, "An Auger analysis of the $\mathrm{SiO}_{2}-\mathrm{Si}$ interface," Journal of Applied Physics, vol. 47, pp. 3028-3037, 1976.

[22] C. W. Gwyn, "Model for Radiation-Induced Charge Trapping and Annealing in the Oxide Layer of MOS Devices," Journal of Applied Physics, vol. 40, pp. 4886-4892, 1969.

[23] M. V. Fischetti, "Generation of positive charge in silicon dioxide during avalanche and tunnel electron injection," Journal of Applied Physics, vol. 57, pp. 2860-2879, 1985.

[24] L. M. Terman, "An investigation of surface states at a silicon/silicon oxide interface employing metal-oxide-silicon diodes," SolidState Electronics, vol. 5, pp. 285-299, 1962. 